\title{
Measurements of water potential and water content in unsaturated crystalline rock
}

\author{
Martin Schneebeli, ${ }^{1}$ Hannes Flühler, Thomas Gimmi, Hannes Wydler, \\ and Hans-Peter Läser \\ Soil Physics, Institute of Terrestrial Ecology, Eidgenössische Technische Hochschule Zürich, Zurich, Switzerland
}

Toni Baer

Nagra, Wettingen, Switzerland

\begin{abstract}
A water desaturation zone develops around a tunnel in water-saturated rock when the evaporative water loss at the rock surface is larger than the water flow from the surrounding saturated region of restricted permeability. We describe the methods with which such water desaturation processes in rock materials can be quantified. The water retention characteristic $\theta(\psi)$ of crystalline rock samples was determined with a pressure membrane apparatus. The negative water potential, identical to the capillary pressure, $\psi$, below the tensiometric range $(\psi<-0.1 \mathrm{MPa})$ can be measured with thermocouple psychrometers (TP), and the volumetric water contents, $\theta$, by means of time domain reflectometry (TDR). These standard methods were adapted for measuring the water status in a macroscopically unfissured granodiorite with a total porosity of approximately 0.01 . The measured water retention curve of granodiorite samples from the Grimsel test site (central Switzerland) exhibits a shape which is typical for bimodal pore size distributions. The measured bimodality is probably an artifact of a large surface ratio of solid/voids. The thermocouples were installed without a metallic screen using the cavity drilled into the granodiorite as a measuring chamber. The water potentials observed in a cylindrical granodiorite monolith ranged between -0.1 and $-3.0 \mathrm{MPa}$; those near the wall in a ventilated tunnel between -0.1 and $-2.2 \mathrm{MPa}$. Two types of three-rod TDR probes were used, one as a depth probe inserted into the rock, the other as a surface probe using three copper stripes attached to the surface for detecting water content changes in the rock-to-air boundary. The TDR signal was smoothed with a low-pass filter, and the signal length determined based on the first derivative of the trace. Despite the low porosity of crystalline rock these standard methods are applicable to describe the unsaturated zone in solid rock and may also be used in other consolidated materials such as concrete.
\end{abstract}

\section{Introduction}

Unsaturated flow phenomena in soils and in the vadose zone receive considerable attention because of their eminent role in the hydrological and biogeochemical cycles. In contrast to the unsaturated zone extending from the soil surface to the aquifer, the corresponding phenomena in rock formations are poorly documented probably due to experimental difficulties and limited accessibility. Using ordinary tensiometers installed within large pieces of the fine porous skeleton of a Rendoll soil, Buchter [1984] showed that the negative water potentials, $\psi$, inside the calcareous matrix respond very rapidly to infiltration and drainage events. A piece of skeleton tapped with a tensiometer acts as a natural large-volume and thick-walled tensiometer cup. Adjacent to rock surfaces exposed to a nonsaturated atmosphere a region with negative water potentials develops even when the geological stratum is under hydrostatic pressures of several megapascals [Baertschi et al., 1991]. Be-

\footnotetext{
${ }^{1}$ Now at Swiss Federal Institute of Snow and Avalanche Research, Davos Dorf, Switzerland.

Copyright 1995 by the American Geophysical Union.

Paper number 95WR01487.

0043-1397/95/95WR-01487\$05.00
}

cause of tunnel or cavern ventilation with ambient air, the rock matrix dries out when the evaporation exceeds the saturated flow from the region surrounding the unsaturated zone. An unsaturated zone may also develop when the pressure in a trapped gas phase increases, for example, as a consequence of methane production or thermal expansion of the air [Finsterle, 1993]. Such transient multiphase transport phenomena are especially relevant if they occur in the vicinity of repositories for chemical or nuclear wastes. The theory for quantifying such phenomena is quite advanced [Eaton et al., 1990; Pruess and Wang, 1987; Finsterle, 1993], but the database for describing unsaturated flow in rock matrices is to our knowledge practically lacking. The objective of this study was the adaptation of soil physical standard methods to the rather different and difficult experimental conditions and requirements of crystalline rock. In particular, we show the usefulness and the limitations of time domain reflectometry (TDR) and thermocouple psychrometry (TP) methods. We extended the usual range of sample desaturation with the pressure membrane technique. Further, we document the technical procedures and provide a database for deriving some of the hydraulic properties characterizing the macroscopically homogeneous granodiorite. Hence this contribution is focused on methodological aspects. In a subsequent study these methods were successfully used in 
situ in the Grimsel test site (GTS), which is the hard rock laboratory of the National Cooperative for the Disposal of Radioactive Waste (Nagra).

\section{Materials and Methods}

\section{Field Site}

The in situ test experiment of the thermocouple psychrometry described below was carried out in a drift at GTS (ventilation-drift (VE), tunnel meter 450) which is a tunnel system $400 \mathrm{~m}$ below ground in the Alpine formation of the Aare granite in central Switzerland [Keusen et al., 1987]. The core materials and the monolith used in the laboratory experiments were obtained from the drift sidewall. The granodiorite at this site has a low intensity of cleavage and is unfractured at the investigated scale. The test site lies between two fractured zones approximately $6 \mathrm{~m}$ apart. The total accessible porosity is of the order of $1 \%$ by volume.

\section{Rock Monoliths}

The laboratory experiments were conducted using granodiorite rock monoliths. The monolith for the thermocouple tests was a cylinder of $24 \mathrm{~cm}$ diameter and $40 \mathrm{~cm}$ height. In addition, we used two rectangular blocks cut from cylindrical blocks with dimensions of approximately $30 \mathrm{~cm}$ length, $15 \mathrm{~cm}$ width, and 4 $\mathrm{cm}$ height.

\section{Water Desaturation Characteristic}

The water desaturation characteristic was determined with the pressure membrane technique [Campbell, 1986]. Three cores of $10.1 \mathrm{~cm}$ diameter and $63 \mathrm{~cm}$ length and four cores of $2.76 \mathrm{~cm}$ diameter and $24 \mathrm{~cm}$ length were drilled out at the site mentioned above. The larger cores were cut in slices of $2 \mathrm{~cm}$ thickness with a diamond saw, the smaller ones in slices of $1 \mathrm{~cm}$ thickness. The surface was flat polished. The diameter and height of the samples were measured with a vernier caliper to a hundredth of a millimeter at three locations and then averaged. The samples were dried at $105^{\circ} \mathrm{C}$ for at least 2 days. The dry weight was determined after cooling in a jar filled with silica gel. Afterward the samples were evacuated for 6 hours, then immersed in water (vacuum maintained during flooding), and then saturated for 2 days under a pressure of $0.6 \mathrm{MPa}$. According to Dullien [1992] and Skagius and Neretnieks [1986] this imbibition method yields the most thorough saturation. The water desaturation characteristic is determined in a pressure membrane apparatus at 15 different pressures covering a range of water potentials from $-0.1 \mathrm{kPa}$ to $-10 \mathrm{MPa}$. Four types of membranes were used with different air entry values. In the low suction range $(0>\psi>-8 \mathrm{kPa})$ the large samples were drained on a porous stainless steel membrane, in the intermediate suction range $(-16>\psi>-69 \mathrm{kPa})$ on a ceramic plate, and in the high suction range $(-200>\psi>$ $-1500 \mathrm{kPa}$ ) on a synthetic fine porous cellophane membrane (trade name, Precision Zephyr Hs Visrex casing, from Viscora, Paris). An apparatus similar to the one described by Coleman and Marsh [1961] for the very high range $(\div 5>\psi>-10$ $\mathrm{MPa}$ ) was constructed. The membrane plate was covered with a membrane filter (trade name, membrane filter RC51, pore size $0.005 \mu \mathrm{m}$, Schleicher and Schüll AG, Feldbach, Switzerland). Only the small samples were used for the measurements in the very high range. Equilibration time was 24 hours for the suction range $0>\psi>-69 \mathrm{kPa}, 48$ hours for the suction

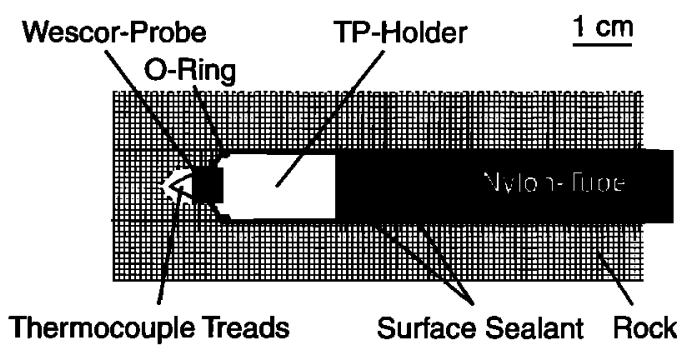

Figure 1. Construction of the thermocouple psychrometer including sensor head and access tube.

range $-0.2>\psi>1.5 \mathrm{MPa}$, and 5 days for the suction range $-2>\psi>-10 \mathrm{MPa}$.

The evaporation loss in ambient air due to handling was initially $15 \% \mathrm{~min}^{-1}$ of the total water content for saturated samples and slowed down with increasing dryness. To minimize the water losses caused by evaporation during the equilibration period in the pressure membrane apparatus, the samples were covered with a plastic sheet. Wet towels were placed on the plastic to keep the air saturated with water. The weighing time was kept minimal and constant. The measuring error due to weighing is less than $1 \%$ of the average water content. Because of the rapid drying in free air, we wetted the samples after each weighing step for a few minutes. This was accomplished by putting the samples into 5 -mm-deep deaired water.

\section{Thermocouple Psychrometers (TP)}

Measuring principle. A thermocouple psychrometer measures the relative humidity within an air-filled cavity which is in equilibrium with the surrounding water phase [Rawlins and Campbell, 1986]. The Kelvin equation defines the relationship between the water potential in the liquid phase, $\psi$, and the vapor pressure in neighboring gas phase, $p$,

$$
\psi=\left[\left(\rho_{w} R T\right) / M_{w}\right] \ln \left(p / p_{0}\right)
$$

where $\rho_{w}$ and $M_{w}$ are the density and the molecular weight of water, $R$ the universal gas constant, and $T$ the absolute temperature. If $p$ equals the saturated vapor pressure $p_{0}$, then $\psi$ is by definition zero, which is the water potential of a free surface of pure water at that particular temperature. It is important to note that the upper (wet) limit of the TP measuring range is of the order of $\psi \approx-0.1 \mathrm{MPa}$; hence there is no reliable overlap with that of tensiometers.

Construction. We used commercially available TPs (Wescor TP 55). The metallic screen cap was removed, and the V-shaped thermocouple wires were bent back into a plane by means of a robust horse hair and the wires were carefully rinsed in purified alcohol. In their original state these wires are occasionally somewhat twisted and coated with impurities, each of which increases the variation of the output signal significantly, especially at high relative humidities, that is, at the wet end of the measuring range. The sensor is mounted onto the tip of the sensor head (Figure 1) which, in turn, is connected with a moderately flexible pressure tubing (OD, 12 $\mathrm{mm}$ ). The critical step is the complete separation of the measuring cavity from the atmosphere of the access borehole.

Installation. The boreholes for the thermocouple psychrometers were drilled into the first $1.6 \mathrm{~m}$ from the rock surface reaching the following depths: $5,10,20,40,80$, and 160 $\mathrm{cm}$. The holes were drilled in these steps: (1) A hollow core drilling bit of OD $12 \mathrm{~mm}$ and ID $8 \mathrm{~mm}$ is drilled into the 
granodiorite with proper mechanical guidance to the installation depth, advancing in steps of $20 \mathrm{~cm}$. After every step at least part of the $8-\mathrm{mm}$ core attached at the bottom of the borehole was left. (2) Nylon tubing of the same ID and OD as the drilling bit was slipped over the remaining core. The friction resulting from twisting the tube is sufficient to break the core loose and to pull it out of the borehole. The first two steps were repeated until the final depth of the sensor was reached. (3) The remaining piece of the core was drilled out with a conical drill bit which prepared the shoulders for the sensor seat (Figure 1). The borehole was sealed with a resin (Sika Primer 1), a prepolymer which reacts with the surrounding moisture by forming waterproof polyurethane. With a special drilling bit the cavity hole (ID, $5.2 \mathrm{~mm}$ ) was sunk to a depth of $7 \mathrm{~mm}$ behind the conical seat shoulders. The cavity was tightened with an $\mathrm{O}$-ring against the access borehole. The volume of the cavity after installation of the sensor was approximately $0.1 \mathrm{~cm}^{3}$. This very small cavity assured a rapid equilibration with the rock matric potential [Millar, 1974] and reduced significantly the problems described by Montazer [1987]. After installation the minimal opening between access tube and rock at the surface was sealed with a silicone sealant. The measurements of the TPs reached a stable value within 2 days. It is essential to keep the temperature differences in the cavity within $\pm 0.01 \mathrm{~K}$ and to shield the wiring and voltmeter carefully against external electromagnetic fields. More elaborate construction details and handling techniques are described by Baer et al. [1992].

The mantle of the monolith for the laboratory study was sealed with the above mentioned resin. At two installation depths, 5 and $19 \mathrm{~cm}$ above the bottom end of the monolith, we installed two TPs on the opposite sides. The installation technique was the same as for the in situ experiment. The tips of the TPs were $5 \mathrm{~cm}$ from the mantle surface.

TP calibration. The individual TP sensors are calibrated in a chamber containing a sodium chloride solution. The relative humidity in the gas phase of this calibration chamber is adjusted by controlling the osmotic potential of the solution. The calibration potential is calculated after Lang [1967]. We used solutions of $0.0,0.02,0.04,0.08,0.16,0.32$, and $0.64 M$ sodium chloride, which covers a water potential range from 0 to -2.76 $\mathrm{MPa}$. The chamber consisted of a porous Teflon block with drilled holes where the assembled sensors could be inserted similar to the final hole in the rock. The form and size of the chamber are important for rapid equilibration, as has been shown by Millar [1971]. For every concentration step a separate chamber was used, soaked with the respective solution. This construction also prevented the pollution of the thermocouple threads with sodium chloride solution.

\section{Time Domain Reflectometry (TDR)}

Principle. The water content $\theta$ in granodiorite ranges from values near zero up to the porosity of 0.01 . To measure water contents in granodiorite we used three-rod probes similar to the ones described by Zegelin et al. [1989] and a calibration procedure as described by Roth et al. [1990]. The dielectric constant $\varepsilon_{\text {vacuum }}$ is 1 in the vacuum, that for air is approximately $\varepsilon_{a}=1.003$, and that for water is $\varepsilon_{w}=78.54$ at $25^{\circ} \mathrm{C}$, and for the water free granodiorite matrix $\varepsilon_{s}$ varies between 4 and 7. The volumetric fraction and spatial arrangement of the three phases define the composite (average) dielectrical constant $\varepsilon_{c}$ :

$$
\varepsilon_{c}=\left[\theta \varepsilon_{w}^{\alpha}+\left(1-\theta_{0}\right) \varepsilon_{s}^{\alpha}+\left(\theta_{0}-\theta\right) \varepsilon_{a}^{\alpha}\right]^{1 / \alpha}
$$

where $\theta_{0}$ is the accessible porosity. The parameter $\alpha$ describes the geometry of the phase distributions and is 0.5 for fairly isotropic media. The basis for a calibration between the measured property $\varepsilon_{c}$ and the variable $\theta$ to be estimated is (2). Note that $\alpha$ and $\varepsilon_{s}$ are within limits adjustable parameters.

Construction of the probes. The probes have three rods, following the arguments of Zegelin et al. [1989]. For depth probe calibration, three $10-\mathrm{mm}$ boreholes were drilled into a granodiorite block of 29.0 by 15.0 by $4.0 \mathrm{~cm}$. The boreholes were $3.0 \mathrm{~cm}$ apart. The inside of the boreholes was coated with a thin film of an electrically conducting silicon grease (trade name, Elekolit, 3M Company) using a rotating vial brush. The first $20 \mathrm{~cm}$ of three $30-\mathrm{cm}$-long copper rods with an OD of 10 $\mathrm{mm}$ was sanded to achieve a slightly conical shape. The surfaces of the rod were cross-ribbed with 0.5 - to $1.0-\mathrm{mm}$-deep grooves and coated with a film of the silicon grease just mentioned. The three rods were twisted and finally hammered into the boreholes. The rods were then connected with a special head bridging the rods to a coaxial cable.

The surface probe consists of three $10-\mathrm{mm}$-wide, $2-\mathrm{mm}$ thick, and 30-cm-long copper stripes glued $4.5 \mathrm{~cm}$ apart to the fine sanded surface of a granodiorite block using the contact glue Brigatex. The block was 27.4 by 15.1 by $4.0 \mathrm{~cm}$. The three surface conductors were connected with a head similar to the one for the depth probes.

TDR calibration experiment. The two air-dried blocks mentioned were first saturated under vacuum with deaired water by capillary rise, then flooded, and finally pressurized with $0.2 \mathrm{MPa}$ for 24 hours. The resulting water content was assumed to approximate total saturation, and a TDR measurement was taken with a Tektronix 1502 B connected with a Macintosh PC to monitor the digitized trace. Different water contents were established by evaporation, first by exposing the blocks to the free atmosphere and at later steps by evaporating them under vacuum in an exsiccator. After each evaporation step the blocks were first exposed to free air for another 24 hours and then tightly wrapped with a polyethylene sheet to allow the moisture to redistribute in the block for 2 to 3 days. After this equilibration the water content in the block was measured by TDR.

Signal interpretation. The travel time of an electromagnetic pulse must be determined from the sudden rise or decrease of the TDR trace, which is the energy reflected from the head and the end of the rod as plotted in the time domain. The signal is digitally recorded, consisting of 251 points on the abscissa and 128 points on the ordinate. This signal is smoothed using a Fourier transform low-pass filter [Press et al., 1986] with a smoothing window of 10 pixels corresponding to 280 ps which equals about $4 \%$ of the entire signal (Figure 2 ).

The width of this window corresponds to the range of the eliminated frequencies. It was kept constant for all signals. If the window is too large, the signal is unacceptably distorted; if it is too small, the signal noise is not suppressed. The maximum difference between the original and the smoothed signal is less than $1.5 \%$. The smoothed signal is then numerically differentiated. The maximum of the first derivative corresponds to the inflection point of the rise of the step signal. The final maximum is determined by fitting a third-order polynomial between the maximum and its neighbor pixels. The difference between the two resulting maxima gives the signal length $l_{s}$ (Figure 2). 


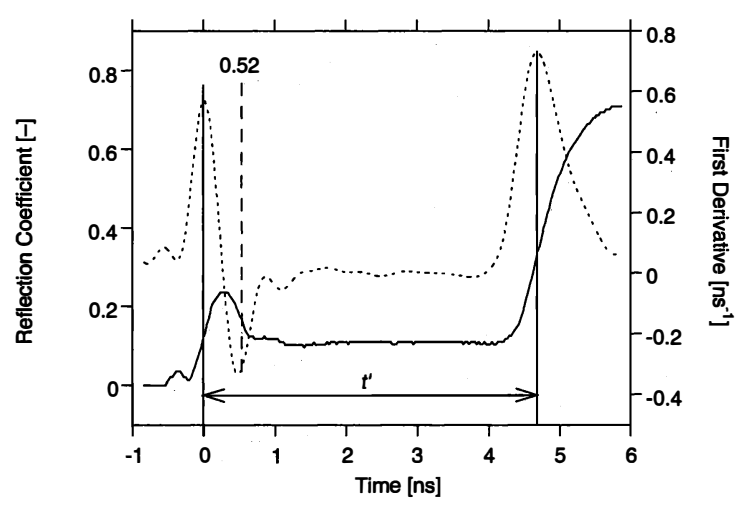

Figure 2. Typical signal of a depth probe. The solid line represents the original signal, and the dashed line the first derivative of the smoothed signal, which allows the evaluation of the signal. The offset $t_{0}$ caused by the head of the probe is $0.52 \mathrm{~ns} ; t^{\prime}=t+t_{0}$.

The signal length $l_{s}$, measured in pixels, is related to the travel time $t$ by

$$
t=\frac{20}{251} \frac{l_{s}}{v_{p}} \frac{d_{d}}{c_{0}}-t_{o}
$$

where $v_{p}$ and $d_{d}$ are instrument constants, $c_{0}$ is the velocity of light in a vacuum, and $t_{o}$ is the offset of the signal caused by the head of the TDR probe. The composite dielectric number $\varepsilon_{c}$ is finally

$$
\varepsilon_{c}=\left(t / t_{a}\right)^{2}
$$

where $t_{a}$ is the travel time of the signal when the probe is in air. Using (4) and assuming an electromagnetically isotropic medium $(\alpha=0.5)$, no additional calibration is needed to determine the volumetric water content $\theta$ from $\varepsilon_{c}$ if the porosity $\theta_{0}$ and the dielectric constants $\varepsilon$ of the different phases are known:

$$
\theta=\frac{\varepsilon_{c}^{\alpha}-\left(1-\theta_{0}\right) \varepsilon_{s}^{\alpha}-\theta_{0} \varepsilon_{a}^{\alpha}}{\varepsilon_{w}^{\alpha}-\varepsilon_{a}^{\alpha}}
$$

Because it was not clear whether this mixing law (5) is valid for such low-porosity rock materials, the independent calibration between volumetric water content $\theta$ and composite dielectric number $\varepsilon_{c}$ on a granodiorite block was made.

\section{Results and Discussion}

\section{Water Desaturation Characteristics $\theta(\psi)$}

At water saturation achieved under vacuum the water content $\theta_{0}$ may be considered as the accessible porosity. The average water content $\theta_{0}$ of the 12 samples was 0.01006 with a coefficient of variation $\mathrm{CV}\left(\theta_{0}\right)$ of $3.1 \%$. The solid density $\rho_{r}$ of all samples was $2.73 \mathrm{Mg} \mathrm{m}^{-3}$ with a $\operatorname{CV}\left(\rho_{r}\right)$ of $0.6 \%$. Neither the $\theta_{0}$ nor the $\rho_{r}$ depended on the sampling distance measured from the drift surface. The moisture retention curve shown in Figure 3 exhibits two distinct relatively steep (with respect to $d \theta / d \psi)$ regions with a different slope, that is, with a larger specific moisture capacity $C(\theta)=d \theta / d \psi$ indicating a bimodal pore size distribution.

A desaturation as observed in the pressure range from -0.1 to $-0.5 \mathrm{kPa}$ would approximately correspond to a drainage of the pores with equivalent diameters of $3.0-0.6 \mathrm{~mm}$. Since no cracks were visible on the sample surfaces, the observed water content changes may be attributed not only to drainage of this largest pore class but also partly to water content changes at the microscopically rough sample surfaces where the meniscii are receding owing to the change in $\psi$ from -0.1 to $-0.5 \mathrm{kPa}$. If a water film of $10 \mu \mathrm{m}$ thickness is removed because of this first drainage step, it would correspond to a $\Delta \theta \approx 0.001$. It is therefore likely that the systematically observed bimodality is an artifact. The $\theta(\psi)$ curves of the individual samples $i$ are not always parallel but do cross over, which means that the volumes $\Delta \theta_{i j}$ occupied by the various pore classes $j$ differ considerably from sample to sample. A pore class in this sense is defined by the limiting equivalent pore diameters of two neighboring pressure levels. In a few cases the water content increased during a desaturation step, which suggests that we operated at the experimental detection limit. It is interesting to note that the $\operatorname{CV}(\theta)$ of the water contents is of the order of $2-3 \%$ with one value at $7 \%(\psi=-0.5 \mathrm{kPa})$, which compares fairly well with the $\theta$ variation of soil samples. In the suction range $-1.0>\psi>-200 \mathrm{kPa}$, virtually no drainage is observed, indicating that pore diameters $d$ in the range of $0.3 \mathrm{~mm}$ $>d>1.5 \mu \mathrm{m}$ are absent, whereas in the range $-0.5>\psi>$ $-5 \mathrm{MPa}(0.6 \mu \mathrm{m}>d>0.06 \mu \mathrm{m})$ the granodiorite samples again lost a substantial portion of their water. According to Meyer et al. [1989] this granodiorite shows three types of pore classes: (1) intragranular or intergranular microcracks without any neoformations (recrystallizations in the cracks), (2) old greenschist microcracks marked with tiny neoformed crystals (mainly epidote), and (3) grain boundary pore spaces which could contribute to the observed macroporosity.

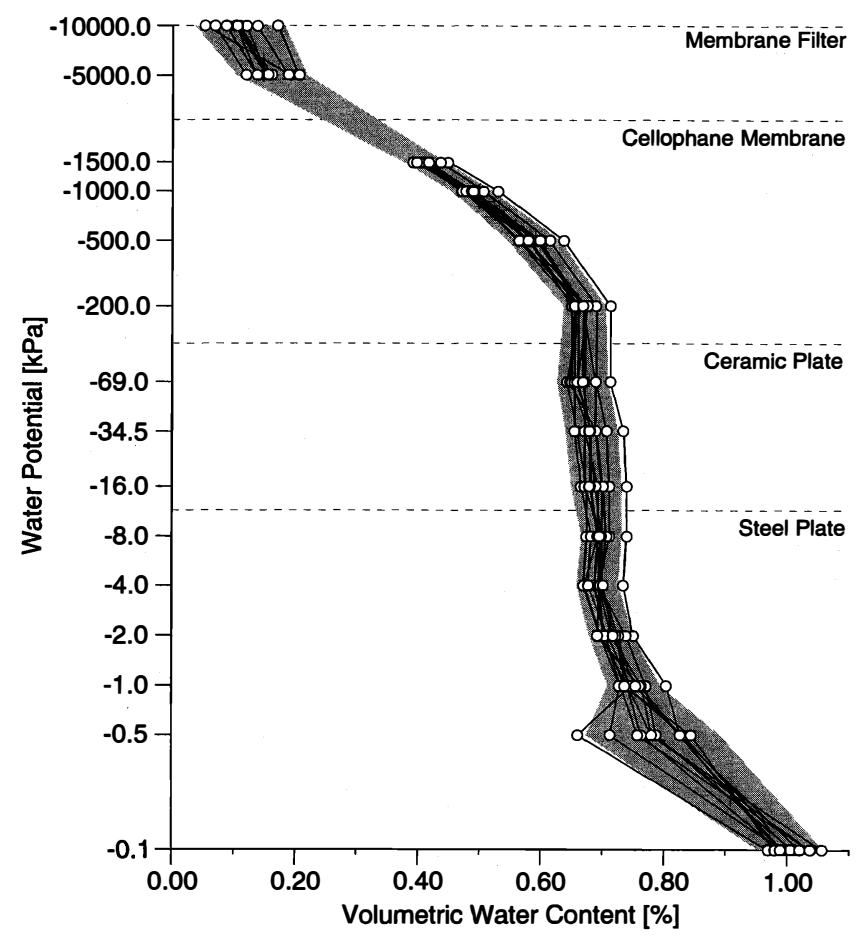

Figure 3. Desaturation curve of the granodiorite rock samples. The samples up to $-1.5 \mathrm{MPa}$ are from the site VE-450, and the high-pressure samples from a nearby site of the same mineralogical and textural composition. The shaded area includes the $95 \%$ confidence interval ( 2 times the standard deviation of the samples at each pressure step). 


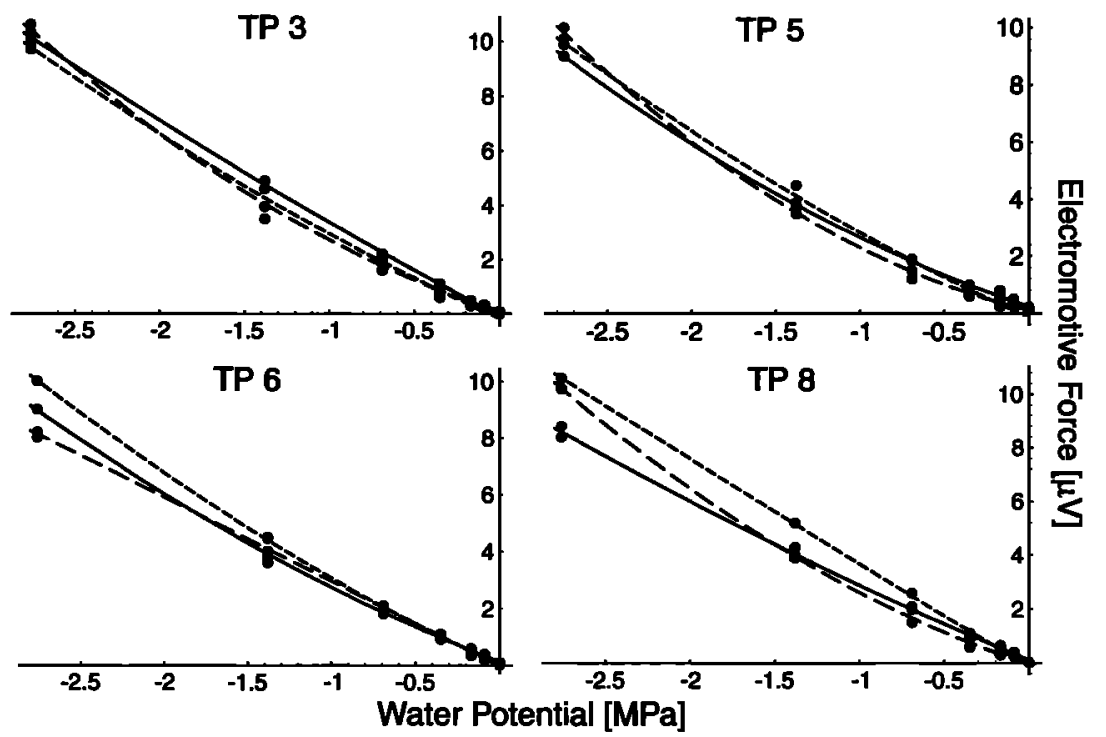

Figure 4. Calibration of the thermocouple psychrometers showing the long-term stability. The water potential is created using variably concentrated sodium chloride solutions. The lines are second-order polynomial regressions. Solid line is calibration before installation, long-dashed line after 170 days exposed in rock, and short-dashed line before installation for a second experiment, stored 90 days in air.

\section{Water Potential Measurements}

TP calibration experiment. The measurements made within the calibration chambers showed that the relationship between the TP output signal (microvolts) and the corresponding water potential is slightly nonlinear (Figure 4), but it can be well represented with a second-order polynomial.

To determine the long-term stability of the TPs, we conducted three calibrations, immediately before installation into rock, after 170 days in resaturating rock, and again after 90 days of storage in air. The resulting coefficients of determination are always $r^{2}>0.993$. The calibration curves taken before installation and after the first and before the second installation of the sensors were fairly stable. Two sensors were stable over the time used within $\pm 0.1 \mathrm{MPa}$; the other two sensors showed larger variations up to $\pm 0.3 \mathrm{MPa}$. Considering

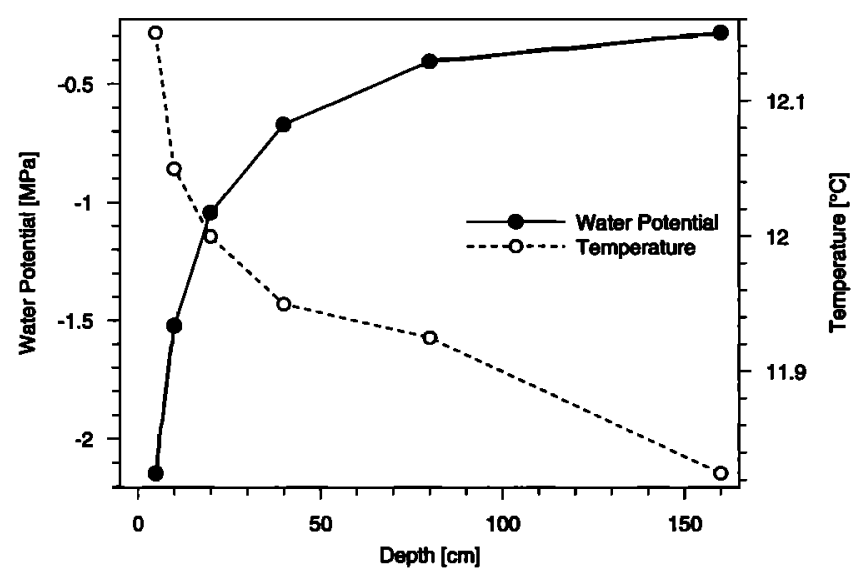

Figure 5. Distribution of the water potential and temperature in the VE-drift of the Grimsel test site. Four consecutive measurements were taken during a period of constant air humidity and temperature and averaged. The standard deviation of the water potential measurements is $0.03 \mathrm{MPa}$. the fragility of these sensors and the susceptibility of such measurements to electromagnetic and temperature disturbances, this reading stability was surprising to us.

In situ and laboratory measurement. In Figure 5 we show the water potentials and temperatures observed in the unsaturated region surrounding the well-ventilated drift at the Grimsel test site, which was kept at a mean relative humidity below $60 \%$ for more than 4 months. At a relative humidity of $60 \%$, measured during the experiment, we expect a corresponding water potential of $\psi \approx-66 \mathrm{MPa}$ within the outermost granodiorite boundary layer. The minimal water potential measured at $5 \mathrm{~cm}$ depth was $-2.2 \mathrm{MPa}$. This shows that the water potential gradient over the first centimeters is very steep. The field site is not at equilibrium. It is likely that moisture transfer at such negative water potentials takes place primarily in the form of vapor diffusion. The temperature in this underground area is stable, with a typical gradient of $2 \mathrm{~K} \mathrm{~m}^{-1}$ between 5 and $10 \mathrm{~cm}$, which goes down to about $0.1 \mathrm{~K} \mathrm{~m}^{-1}$ between 80 and $160 \mathrm{~cm}$. The maximal error introduced by the temperature gradient in the sensor is $\approx 0.1 \mathrm{MPa}$.

The time response due to capillary rise and evaporative drainage is demonstrated by means of the measurements taken in a cylindrical granodiorite monolith (Figure 6). This column was air-dried during 70 days at relative air humidity of about $50 \%$. Several days after instrumentation, one end was put $1 \mathrm{~cm}$ deep in deionized water for $\mathbf{5 0}$ hours. Then it was wrapped completely in polyethylene foil for an observation period of 21 days, and at the end of the experiment it was again put in water. The top $20 \mathrm{~cm}$ of the monolith was at water potentials of less than $-3 \mathrm{MPa}$. The TPs at $19 \mathrm{~cm}$ above the water table are within reach of the rising water front. The curves of the two TPs at the same height differ by less than $0.1 \mathrm{MPa}$.

The TP measurements obtained on site and those from the laboratory experiments show (1) a good reproducibility of the calibration signal with the method used, (2) a consistent signal and rapid change of potentials in a laboratory experiment conducted in a granodiorite rock column, and (3) a good sen- 


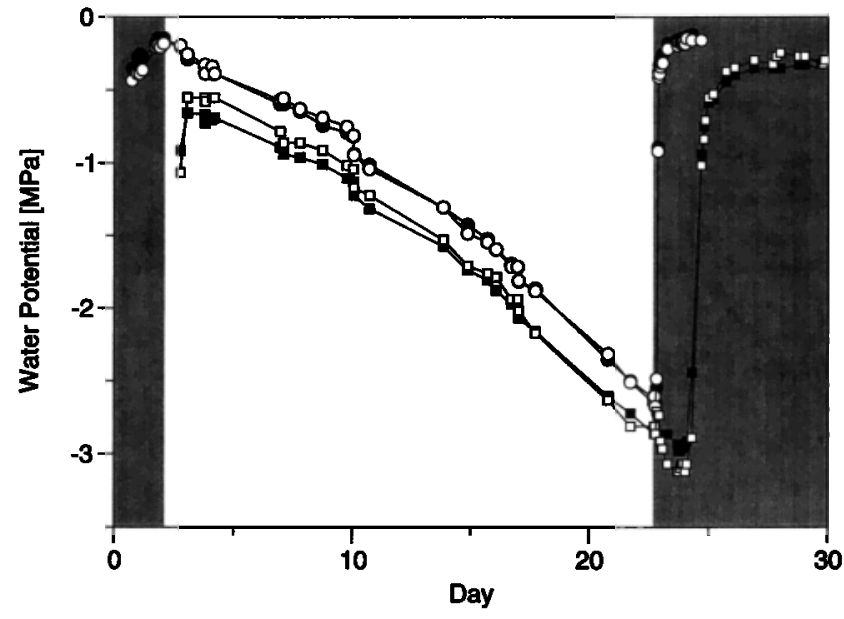

Figure 6. Temporal changes of the water potential in the unsaturated granodiorite monolith (laboratory column). Circles refer to $5 \mathrm{~cm}$ height above bottom, squares to $19 \mathrm{~cm}$ height. The shaded areas indicate days when the column was put in 1-cm-deep water. From day 2.1 to day 22.7 the column was sealed for moisture redistribution.

sitivity within the range of water potentials occurring near the surfaces of ventilated tunnels.

Water content measurements. The relationship between the water content and the composite dielectric constant $\varepsilon_{c}$ is shown in Figures 7 and 8 for the depth and the surface probe calibration experiments carried out on the two granodiorite blocks.

The $\theta\left(\varepsilon_{c}\right)$ relationship of the depth probe is nonlinear. In the desaturated range $(\theta<0.008)$ the slope of the observed $\varepsilon_{c}(\theta)$ corresponds to that expected based on a geometry factor of $\alpha=0.5$. At high saturation degrees the slope appears to be steeper, which possibly implies a closer alignment of the electromagnetic field with that of the liquid phase. Another crucial value in this calibration model besides $\alpha$ is the dielectric constant of the solid matrix $\varepsilon_{s}$, which may vary owing to variations

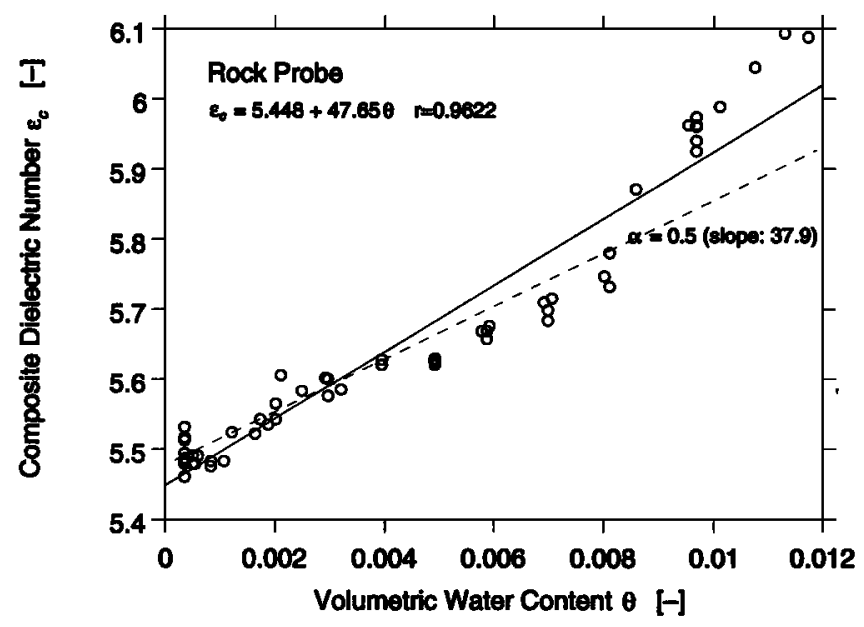

Figure 7. Composite dielectric constant $\varepsilon_{c}$ measured with TDR installed in a granodiorite block with defined water contents. The straight line shows the regression line. The dashed line is calculated using a geometry factor $\alpha=0.5$ and a dielectric constant $\varepsilon_{s}=5.55$ using (5).

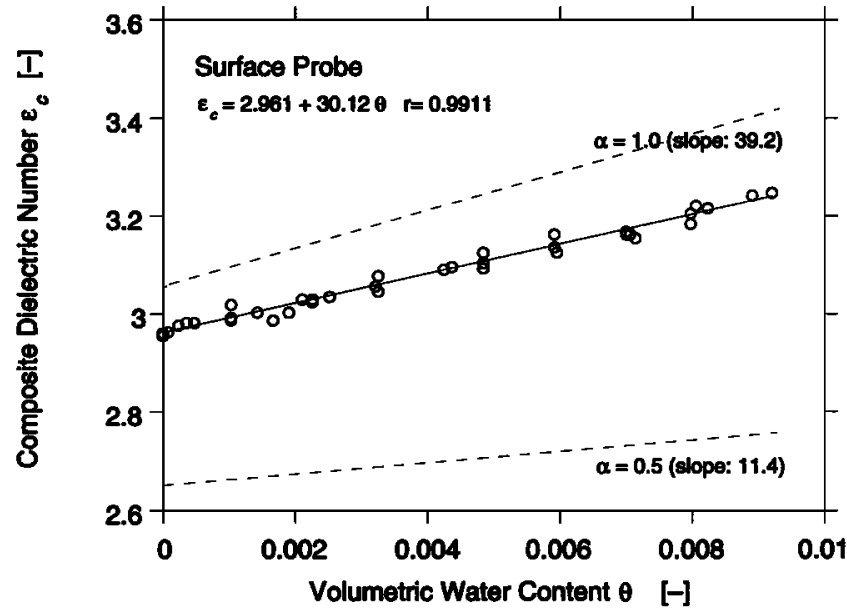

Figure 8. Composite dielectric constant $\varepsilon_{c}$ measured with TDR on the surface of a granodiorite block with defined water content. The solid line shows the regression line. It corresponds to a geometry factor $\alpha=0.88$ and a dielectric constant of the rock $\varepsilon_{s}=5.15$. The dashed lines were calculated using geometry factors $\alpha=0.5$ and $\alpha=1.0$ and a dielectric constant $\varepsilon_{s}=5.15$ using (5).

in density and crystallographic composition. This is also supported by the calibrations, because the two blocks used are not from the same location. The slope of $\varepsilon_{c}(\theta)$ observed in the surface probe calibration experiment is linear and smaller than that of the depth probe. The $\alpha$ corresponding to the observed slope is of the order of 0.88 . Hence the obviously asymmetric phase distribution on the two faces of the copper stripes-free air and rock-water-air may account for this difference.

\section{Conclusions}

The calibration tests presented in this paper show that the water potential in unsaturated granodiorite, a crystalline rock, can be measured very sensitively and reproducibly, provided the water potential is more negative than $-0.1 \mathrm{MPa}$ and the signal from the thermocouple psychrometer is shielded from electromagnetic noise. The relative uncertainty in measurements improves with more negative values of $\psi$, since the absolute uncertainty remains nearly constant $(\approx \pm 0.1 \mathrm{MPa})$. Stable temperature conditions and well-shielded wiring and equipment are essential for making such measurements. It was not possible to measure in the tensiometer range. With TDR it is possible to measure water content changes in crystalline rock. Volumetric water content changes of approximately 0.001-0.002 can be detected, but the detectability is clearly at its limit. On the basis of the calibration with granodiorite blocks we decided to use this technique for an in situ experiment which will be reported in a future paper. The moisture characteristic of granodiorite can possibly be used in the same sense and very likely with the same problems as in the case of unsaturated soils. The apparent bimodality of the pore size distribution is an experimental artifact caused by the large ratio between the outer surface area of the sample and the area of the pores.

Acknowledgments. These investigations were funded by Nagra, the National Cooperative for the Disposal of Radioactive Waste, Switzerland, and by the ETH Zürich. We thank S. Vomvoris and B. Frieg 
(both Nagra) for the professional and very supportive project management and Hans Abplanalp (Nagra) for the help and the technical expertise. We are grateful for the instrumental help provided by the Plant Pathology Group at ETHZ. The manuscript was improved by the comments of three anonymous reviewers.

\section{References}

Baer, T., M. Schneebeli, H. Abplanalp, H. Wydler, and H. Flühler, Wassergehalt und Wasserpotential in ungesättigtem Granit: Messtechnik, Nagra internal report, Nagra, Wettingen, Switzerland, 1992.

Baertschi, P., W. R. Alexander, and H. Dollinger, Uranium migration in crystalline rock: Capillary solution transport in the granite of the Grimsel test site, Switzerland, Nagra Tech. Rep. 90-15, Nagra, Wettingen, Switzerland, 1991.

Buchter, B., Untersuchung des Wasserhaushaltes in einem inhomogenen, anisotropen Sickersystem, dargestellt an einem RendzinaBoden, Ph.D. thesis, Eidg. Tech. Hochsch., Zurich, 1984.

Campbell, A., Water retention: laboratory methods, in Methods of Soil Analysis, part 1. Physical and Mineralogical Methods, 2nd ed., edited by A. Klute, chap. 26, pp. 635-662, Am. Soc. Agron./Soil Sci. Soc. of Am., Madison, Wis., 1986.

Coleman, J. D., and A. D. Marsh, An investigation of the pressure membrane method for measuring the suction properties of soil, $J$. Soil Sci., 12, 343-362, 1961.

Dullien, F. A. L., Porous Media: Fluid Transport and Pore Structure, 2nd ed., Academic, San Diego, Calif., 1992.

Eaton, R. R., N. E. Bixler, and R. J. Glass, Predicting flow through low-permeability, partially saturated, fractured rock-A review of modeling and experimental efforts at Yucca Mountain, in Hydrology of Low Permeability Environments, Sel. Pap. Hydrogeol., vol. 2, edited by S. P. Neuman and I. Neretnieks, pp. 239-268, Heise, Hannover, Germany, 1990.

Finsterle, S., Inverse Modellierung zur Bestimmung hydrologischer Parameter eines Zweiphasensystems, Mitt. Versuchsanst. Wasserbau Hydrol. Glaziol. Eidg. Tech. Hochsch. Zurich, 121, 1-205, 1993.

Keusen, H. R., J. Ganguin, P. Schuler, and M. Buletti, Grimsel test site geology, Nagra Tech. Rep. NTB 87-14E, Nagra, Wettingen, Switzerland, 1987.

Lang, A. R. G., Osmotic coefficients and water potentials of sodium chloride solutions from 0 to $40^{\circ} \mathrm{C}$, Aust. J. Chem., 20, 2017-2023, 1967.

Meyer, J., M. Mazurek, and W. R. Alexander, Petrographic and mineralogical characterisation of fault zones AU 96 and AU 126, in Laboratory Investigation in Support of the Migration Experiments at the Grimsel Test Site, PSI Ber. 28, edited by M. H. Bradbury, pp. 3-25. Paul Scherrer Inst., Wurenlingen, Switzerland, 1989.
Millar, B. D., Improved thermocouple pychrometer for the measurement of plant and soil water potential, II, Operation and calibration, J. Exp. Bot., 22(73), 891-905, 1971.

Millar, B. D., Improved thermocouple psychrometer for the measurement of plant and soil water potential, III, Equilibration, J. Exp. Bot., 25(73), 1070-1084, 1974.

Montazer, F., Monitoring hydrologic conditions in the vadose zone in fractured rocks, Yucca Mountain, Nevada, in Flow and Transport Through Unsaturated Fractured Rock, Geophys. Monogr. Ser., vol. 42, edited by D. D. Evans, and T. J. Nicholson, pp. 31-42, AGU, Washington, D. C., 1987.

Press, W. H., B. P. Flannery, S. A. Teukolsky, and W. T. Vetterling, Numerical Recipes. Cambridge Univ. Press, New York, 1986.

Pruess, K., and J. S. Y. Wang, Numerical modeling of isothermal and nonisothermal flow in unsaturated fractured rock- $\mathbf{A}$ review, in Flow and Transport Through Unsaturated Fractured Rock, Geophys. Monogr. Ser., vol. 42, edited by D. D. Evans, and T. J. Nicholson, pp. 11-21. AGU, Washington, D. C., 1987.

Rawlins, S. L., and G. S. Campbell, Water potential: Thermocouple psychrometry, in Methods of Soil Analysis, Part 1, Physical and Mineralogical Methods, 2nd ed., edited by A. Klute, chap. 24, pp. 597618, Am. Soc. of Agron./Soil Sci. Soc. of Am., Washington, D. C., 1986.

Roth, K, R. Schulin, H. Flühler, and W. Attinger, Calibration of time domain reflectometry for water content measurement using a composite dielectric approach, Water Resour. Res., 26(10), 2267-2273, 1990.

Skagius, K, and I. Neretnieks, Porosities and diffusivities of some nonsorbing species in crystalline rocks, Water Resour. Res., 22(3), 389-398, 1986

Zegelin, S. J., I. White, and D. R. Jenkins, Improved field probes for soil water content and electrical conductivity measurement using time domain reflectometry, Water Resour. Res., 25(11), 2367-2376, 1989.

T. Baer, Nagra, Hardstrasse 73, CH-5430 Wettingen, Switzerland.

H. Flühler, T. Gimmi, H. Wydler, H. P. Läser, Institute of Terrestrial Ecology, ETHZ, Grabenstrasse 3, CH-8952 Schlieren, Switzerland.

M. Schneebeli, Swiss Federal Institute for Snow and Avalanche Research, CH-7260 Davos Dorf, Switzerland. (e-mail: mschneeb@slf.ch)

(Received September 13, 1994; revised May 1, 1995; accepted May 9, 1995.) 